\title{
Modelling Commercial Banks Liquidity Management Using Stochastic Programming
}

\author{
Caston Sigauke ${ }^{1}$, Daniel Maposa ${ }^{2} \&$ Wifred Chagwiza ${ }^{3}$ \\ ${ }^{1}$ School of Mathematical and Computer Sciences, University of Limpopo (Turfloop Campus), Sovenga, South \\ Africa \\ ${ }^{2}$ School of Business and Economics, Monash South Africa (A campus of Monash University, Australia), \\ Roodepoort, South Africa \\ ${ }^{3}$ Department of Business Studies, Bindura University of Science Education, Bindura, Zimbabwe \\ Correspondence: Daniel Maposa, School of Business and Economics, Monash South Africa (A campus of \\ Monash University, Australia), Private Bag X60, Roodepoort, 1725, South Africa. Tel: 27-11-950-4295. E-mail: \\ danmaposa@gmail.com
}

Received: February 28, 2012

Accepted: March 17, 2012

Published: May 1, 2012

doi:10.5539/ijbm.v7n9p49

URL: http://dx.doi.org/10.5539/ijbm.v7n9p49

\begin{abstract}
In this paper a stochastic programming framework for liquidity management of commercial banks in Zimbabwe is developed. The paper sets out to explain an important financial planning model for liquidity management; in particular it discusses why in practice optimum planning models are used. The ability to build an integrated approach which combines treasury security assets models with that of income generating decisions have proved desirable and more efficient in that it can lead to better liquidity decisions. The role of uncertainty and quantification of risk in these planning models is considered.
\end{abstract}

Keywords: stochastic programming, liquidity management, uncertainty, risk

\section{Introduction}

This paper investigates the use of stochastic programming (SP) to optimize the liquid asset portfolio for commercial banks in Zimbabwe. The paper discusses the development, implementation and validation of scenario-based stochastic programming models for actively managing liquid asset portfolios of treasury bills, treasury notes and treasury bonds. Stochastic programs have several attractive features that make them applicable in liquid asset portfolio management problems. The major aim is to develop appropriate two-stage stochastic programming models to manage commercial bank liquidity positions. The analysis of current liquidity position of the commercial banks, a forecast of potential deposit withdrawals, and a forecast of loan demand and review of expected interest rate trends is crucial.

The goal of stochastic programming is to find some policy that is feasible for all the possible data instances and maximizes the expectation of some function of decisions and the random variables. Liquidity of a firm is measured by its balance plus marketable securities that can be quickly converted into cash, as well as other cash generating assets, such as debtors and stock. Liquidity is the immediate availability of funds without the need to sell financial instruments under inappropriate conditions. Hence stochastic programming can be employed as a tool to manage the bank's ability to repay loans to its creditors when due or requested (Klaassen; 1998). Previous work done on this area includes that of Golub et al., 1995; Korhonen, 2001; Frauendorfer and Schurle, 2003; Topaloglou et al., 2008; Castro, 2009; Balibek and Koksalan, 2010.

The rest of the paper is organized as follows. Section 2 gives some background information on liquidity. Section 3 describes the stochastic programming models while Section 4 gives a brief analysis of the results. The conclusion is covered in section 5 .

\section{Background}

Financial disasters (e.g. the collapse of Trust Bank Corporation Limited, Barbican Bank Limited, CFX Bank Limited, CFX Merchant Bank, Intermarket Banking Corporation Limited, Intermarket Building Society, Intermarket Discount House, Royal Bank of Zimbabwe Limited, Time Bank Zimbabwe Limited, etc and the 
subsequent establishment of the Zimbabwe Allied Banking Group (ZABG)) in the financial and banking sector in Zimbabwe in 2003 has been the major reason for having appropriate risk management techniques in place (RBZ Annual Report, 2006). The Reserve Bank of Zimbabwe (RBZ) made it clear in 2003 that banks must implement a risk management and analysis infrastructure that is fully integrated with their daily risk management.

Managing liquidity is among the most important activities conducted by banks. The importance of liquidity transcends the individual bank, since a liquidity shortfall at a single institution can have system-wide repercussions. For this reason, the analysis of liquidity requires bank management not only to measure the liquidity position of the bank on an ongoing basis but also to examine how funding requirements are likely to evolve under various scenarios, including adverse conditions (Basel Committee on Banking Supervision, February 2000; Fielitz and Loeffler, 1979).

\section{The Stochastic Programming (Sp) Model}

We start with a known volume of cash to invest and face a known set of interest rates. The first period involves the investment of wealth into the three treasury security assets, and is exposed to the first event occurring at the end of period 1 and there the portfolio manager makes a set of decisions in light of the new conditions. In this case, an event is defined by a set of interest rates and a cash flow that imposes a new portfolio size constraint. This has been elaborated by the first-stage model shown in figure 1. We assume that the bank has invested all its monies in three security assets which are treasury bills, treasury notes and treasury bonds. Treasury security assets may be used as income generating assets and are susceptible to income tax and capital gains tax. Under these treasury security assets, we have categorized treasury bonds into seven parts. The criterion that has been used to categorize these bonds is through their maturity dates and their types. We formulate the two-stage SP model.

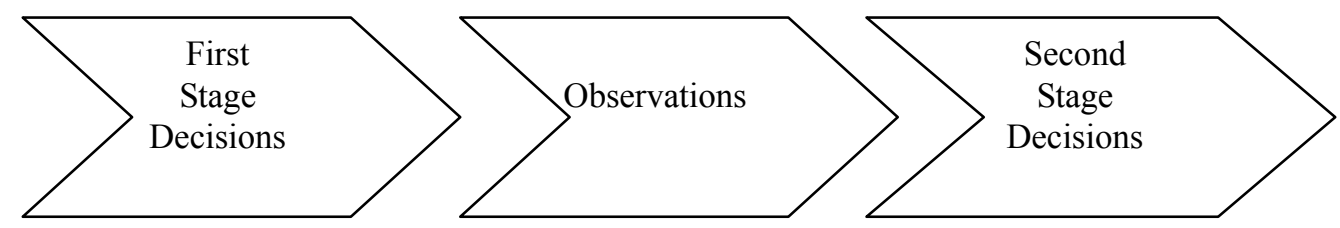

Figure 1. Phases in two-stage stochastic programming model

To ensure that the continuity assumption is not compromised, we formulate constraints reflecting feasible attainment levels for the liquidity variables. In period 1, the objective function is nonlinear and in the second-stage SP model, we have linear variables. The upper and lower limits on asset acquisition or sale are formulated so that the viability of the assumed constant risk premium yield structures is maintained. Liquidity variables are expected to be continuous (Leornard and Long, 1995). The full model is given in the appendix with equations (1) up to (63).

\section{Discussion and Analysis of Results}

Many reasonable variations have been used for validation and the factors which were included were the assumptions about the problem that seem most reasonable, the estimates of the parameters of the model that seem most reliable and the degree of detail desired in the model.

\subsection{Static Tests}

In these tests we examined the in-sample performance of the alternative security investment strategies within a postulated scenario set for the random variables. We investigated the results of the portfolio problem at a specific point in time. In the static tests we considered portfolio selection problems that started with a cash endowment in Zimbabwe dollars (Z\$). The setup of the numerical experiments was through collecting historical data of monthly treasury security asset returns. The data (January 2006 to June 2007) was used to determine the statistics of these random variables and their correlations.

\subsection{Dynamic Tests}

Dynamic tests repeatedly apply the models in backtesting experiments using data on a rolling horizon basis for the period of four months. The simulations started with an initial cash endowment in the investor's reference currency Z\$. The optimization model was solved and the optimal portfolio composition was recorded. On the basis of these new observations, finance and accounting calculations were computed so as to settle outstanding investment decisions of the previous month, and the resulting cash positions were updated. We repeated the 
procedure for the next month, starting with the new portfolio. A new set of scenarios was computed and the optimization model was resolved using the data of the new scenario set and the new portfolio composition.

\subsection{Analysis of Decision Variables}

\subsubsection{Analysis of Deposit Rates}

The deposits were divided into categories on the basis of their probabilities of withdrawal. We had hot money, vulnerable deposits and stable deposits. Hot money is deposits almost certain to be withdrawn within the planning period. Vulnerable deposits are those deposits with some appreciable possibility of withdrawal, but in which deposit withdrawal would not be a certainty or a near certainty. All large deposits should be viewed as vulnerable, given their potential for disrupting the liquidity position of the commercial bank. Stable deposits are the residual and those that are neither hot money nor vulnerable. The cash held by the bank $\left(C_{B a n k}^{T-1}\right)$ at the end of each day solely depends on total deposits and deposit withdrawals on that day. As per RBZ statutory requirements, the everyday total deposits are apportioned and the bank is required to deposit $40 \%\left(D_{R B Z}^{T}\right)$ of its total deposits received into RBZ reserve account and remain with the $60 \%$ for its own use.

\subsubsection{Analysis of Lending and Borrowing Rates}

The interbank borrowings ( $I_{\text {borr }}^{T}$ ) largely depend on rate of demand on deposit withdrawals and cash position of the bank. The higher the interbank borrowing, the more the bank liquidity position is increased. The bank may lend member and non-member banks and this is referred to as interbank lending ( $I_{\text {lend }}^{T}$ ). The central bank RBZ offers discount window credits ( $Q_{R B Z}^{r}$ ) to cash strapped financial institutions and attached with interest rates.

\subsubsection{Analysis of Liquid Assets}

Any decision the commercial bank is going to make has to be governed by the value of the net liquid assets the institution is holding. The value of treasury security assets to be bought ( $A_{1 b_{1}}, A_{2 b_{1}}, A_{3 b_{1}}^{m}, A_{1 b_{2 w_{1}}}, A_{2 b_{2 w_{1}}}, A_{3 b_{2 w_{1}}^{m}}^{m}$ ), treasury security assets sold ( $A_{1 S_{u d w_{1}}}, A_{2 S_{u d w_{1}}}, A_{3 S_{u d w_{1}}^{m}}^{\text {) }}$ and treasury security assets held ( $A_{1 h_{u d w}}, A_{2 h_{u d m}}, A_{3 h_{u d w}}^{m}$ ) depends on the prevailing market conditions and the financial institution's position.

\subsection{Analysis of Models Constraints}

\subsubsection{Activity Level Constraints}

The activity level constraints prevent the model from selling more of treasury security assets than is held. At the start of second period, the portfolio manager can decide to sell or hold treasury security assets previously purchased, but the volume which can be sold or held is constrained by the amount purchased. A decision must be made for each event that can occur at the start of period 2 . We formulate equations for each event $\left(w_{1}=1,2,3\right)$ and each asset. Then the same applies to treasury bonds for each category $(m=1,2,3,4,5,6,7)$. The constraints are (64), (65) and (66):

$$
\begin{aligned}
& -A_{1 b_{1}}+A_{1 s_{u d w}}+A_{1 h_{u d w \mathrm{I}}}=0 \\
& -A_{2 b_{1}}+A_{2 s_{u d v}}+A_{2 h_{u d w}}=0
\end{aligned}
$$




$$
-A_{3 b_{1}}^{m}+A_{3 s_{u d w_{1}}}^{m}+A_{3 h_{u d w_{1}}}^{m}=0 \text { for } u=1 \text { and } d=2
$$

\subsubsection{Pledging Constraints}

As per RBZ statutory instrument, all commercial banks are required to hold collateral security for the acquisition of certain types of liabilities. Reserve requirements are as follows; deposit in RBZ, keep cash for daily transactions, lend or borrow overnight (interbank transactions), borrow overnight from RBZ, trade qualifying short term government bonds, buy new issues of qualifying short term government bonds from RBZ. The basic reserve requirement is to deposit a portion of the daily demand deposit in RBZ. Interest is received on this deposit according to a variable scale. The bank must fulfill their weekly and monthly reserve requirements which are, $\left(F_{R B Z}^{k}\right)$ and $\left(\pi_{R B Z}^{\gamma}\right)$ respectively. Otherwise, if the bank fails to meet the reserve requirements, it faces weekly and monthly penalties which are, $\left(\phi_{R B Z}^{k}\right)$ and $\left(\phi_{R B Z}^{\gamma}\right)$ respectively from RBZ. Commercial banks are allowed to keep certain types of short term government bonds and are encouraged to buy new issues of such treasury security assets at a discount. We have formulated constraints on total amount deposited in RBZ in week $k$ shown in constraint (20), fulfillment of reserve requirements in week $k$ in constraint (21) and fulfillment of reserve requirements in current month in constraint (22).

\subsubsection{Cash Flow Constraints}

The sources of cash flow include the sale of assets or the issuance of liabilities. The uses of cash flow are represented by the purchase of assets. In most cases, the cash outflow is less than the inflows and thus the bank will have cash held for other uses or as reserves. Constraint (23) allows the bank to calculate their daily transactions and know their daily cash flow position.

\subsubsection{Portfolio Composition Constraints}

In the second period, the portfolio consists of treasury securities held over from the first period plus treasury securities purchased at the start of the second period. The dollar volume of these assets is constrained by the limit on portfolio size, which resulted from random cash inflow and or outflow in the first period. We assume that the income earned on treasury securities held in the first period is available for reinvestment in the second period. The constraints (67), (68) and (69) focus on volume limits of treasury security assets per period with respect to different scenarios. The constraints (24), (25) and (26) explain that the assets bought in period one are supposed to be less than the probability that event one will occur. Leornard and Long (1995) pointed out that on using the method of Lagrange, we come up with an optimization model under equality constraints and thus we have constraints (2), (3) and (4) which were obtained through differentiation of the Lagrange objective function with respect to the appropriations.

$$
\begin{aligned}
& -A_{1 y_{u m}} A_{1_{b 1}}-A_{1 g_{u d w}} A_{1 S_{u d v_{1}}}+A_{1 h_{u d w}}+A_{1 b_{u w}} \leq V_{u w_{1}} \\
& -A_{2 y_{u v 1}} A_{2_{b 1}}-A_{2 g_{u d w 1}} A_{2 S_{u d w_{1}}}+A_{2 h_{u d w_{1}}}+A_{2 b_{u w}} \leq V_{u w_{1}} \\
& -\sum_{m} A_{3 y_{u m}}^{m} A_{3_{b 1}}^{m}-\sum_{m} A_{3 g_{u m}}^{m} A_{3 S_{u d w_{1}}}^{m}+\sum_{m} A_{3 h_{u d w_{1}}}^{m}+\sum_{m} A_{3 b_{u w_{1}}}^{m} \leq V_{u w_{1}}
\end{aligned}
$$

$m=1, \ldots ., 7 \quad u=1,2 \quad d=2 \quad w_{1}=1,2,3$

\subsubsection{Liquidity Capability Constraints}

A liquidity capability constraint has been included in the model to ensure that the bank maintains adequate liquid assets for projected and unanticipated deposit withdrawals or credit demands. The changes in net liquid assets must be matched dollar-for-dollar with changes in deposits. The liquidity capability constraint provides that net liquid assets should be no less than a given percentage of total assets the commercial bank has. In this respect, the management has the mandate and ability to change the amount of liquidity, based upon relevant changes in 
market conditions, simply by varying the proportion of assets devoted to liquidity. Hence the inclusion of this constraint is to shadow price that is useful in making decisions regarding the correct amount of liquidity and the constraints are (36), (37) and (38).

We developed portfolio composition constraints, which prevent undue reliance on certain liquidity instruments. The constraints limit the amount of funds invested in security assets. We assumed that the commercial bank has at least invested in each security asset. The constraints are (7), (8) and (9).

We formulated 'turnover constraints' which explain the expected returns from the investment as given in Howison et al. (1995). The constraints (57) and (58) were the budget constraints under different scenarios. They were meant to compare the amount by which the new portfolio may differ from the previous portfolio.

\subsubsection{Maturity Constraints}

The maturity constraints reflect the subjective evaluation of future economic conditions and are to compensate partially for the absence of a multiperiod framework. The maturity bucket can be devised and used to divide the portfolio of assets and liabilities into subcategories. The reason behind this idea is to have maturity buckets that allow the efficient and effective way of managing the assets and liabilities concerned. However, the use of maturity buckets has some drawbacks. The first drawback is that not all assets in a bucket will mature on the same date. Some assets and liabilities will be repriced sooner or later than others, with consequent changes in net interest income from day to day. Hence it is necessary to shorten the time horizon to a one-day period to completely capture net interest effects of interest rate changes. The constraints are (70), (71) and (72).

$$
\begin{gathered}
\operatorname{Min}_{1} \leq \vartheta_{1} A_{1 h_{\text {udw }}} \leq \operatorname{Max}_{1} \\
\operatorname{Min}_{2} \leq \vartheta_{2} A_{2 h_{u d w_{2}}} \leq \operatorname{Max}_{2} \\
\operatorname{Min}_{3 m} \leq \sum_{m} \vartheta_{3}^{m} A_{3 h_{u d w_{2}}}^{m} \leq \operatorname{Max}_{3 m}
\end{gathered}
$$

\subsubsection{Securities Gain (Loss) Constraints}

The security gain or loss constraints limit the losses on sale of treasury securities. The loss constraints provide protection against the worst possible occurrence and do not consider its probability. We assume that the maximum possible loss coefficient occurs when the event with the highest interest rates occurs. The constraints are (73), (74) and (75) respectively.

$$
\begin{aligned}
& -A_{1 g_{\text {ud }}} A_{1 S_{\text {ud }}}-A_{1 g_{\text {udw }}} A_{1 h_{\text {udw }}}-A_{1 g_{\text {ud }}} A_{1 b_{u m y}} \leq L \\
& -A_{2 g_{u d w_{1}}} A_{2 S_{u d w_{1}}}-A_{2 g_{\text {udw }}} A_{2 h_{u d w_{1}}}-A_{2 g_{u d v_{1}}} A_{2 b_{u m}} \leq L \\
& -A_{3 g_{u d w_{1}}}^{m} A_{3 S_{u d w_{1}}^{m}}^{m}-A_{3 g_{u d v_{1}}}^{m} A_{3 h_{u d w_{1}}}^{m}-A_{3 g_{u d w_{1}}}^{m} A_{3 b_{u m}}^{m} \leq L
\end{aligned}
$$

\section{Conclusion}

In this paper, a two-stage stochastic programming model to manage liquidity of commercial banks in Zimbabwe was developed and implemented. The Lagrange objective function to optimize the treasury security assets which consisted of treasury bills, treasury notes and treasury bonds was used. The bonds were categorized according to their types and maturity dates. The bonds were in seven categories. After the formulation of the treasury security asset linear program, the two-stage stochastic program was developed. The assumption made was that a commercial bank starts with an initial cash endowment and the portfolio does not contain any other assets. Two periods were considered. The first period was the treasury security investment stage and the second period involved the treasury security asset portfolio exposed to two events with scenarios. The model contained variables on cash inflow and cash outflow, treasury securities and expected security returns. The model validation and model enrichment were done through employing the static and dynamic tests. The analysis of lending rates, deposit rates and liquid assets were also done. Further research needs to be done when the security portfolio contains more than three assets. 
A process of liquidity risk control was defined. The process involved development of new stochastic programming models, and the validation and refinement of developed models. This process involved defining and setting limits to liquidity risk. Further research can be done to characterise the realistic problems. Thus it is very important to set up stochastic programming models that incorporate more consideration of uncertainties. For example, to the portfolio selection problem, in addition to the usual interest rate changes, uncertainty in the timing and amount of cashflows, changes in the default and other premia risk should be considered.

\section{Acknowledgements}

The authors are grateful to the Reserve Bank of Zimbabwe, Central Statistical Office (Zimbabwe) officials for providing data and information and to the numerous people who assisted in making comments on this paper.

\section{References}

Balibek, E., \& Koksalan, M. (2010). A multi-objective multi-period stochastic programming model for public debt management. European Journal of Operational Research, 205, 205-217. http://dx.doi.org/10.1016/j.ejor.2009.12.001

Basel Committee on Banking Supervision, Basel February 2000. Retrieved from: http://www.bis.org/publ/bcbs69.pdf

Castro, J. (2009). A stochastic programming approach to cash management in banking. European Journal of Operational Research, 192, 963-974. http://dx.doi.org/10.1016/j.ejor.2007.10.015

Fielitz, B. D., \& Loeffler, T. A. (1979). Financial Management. John Wiley \& Sons Ltd, London.

Francis, J. C. (1991). Investments Analysis and Management. McGraw Hill Inc, New York.

Frauendorfer, K., \& Schurle, M. (2003). Management of non-maturing deposits by multistage stochastic programming. European Journal of Operational Research, 151, 602-616. http://dx.doi.org/10.1016/S0377-2217(02)00626-4

Golub, B., Holmer, M., McKendall, R., Pohlman, L., \& Zenios, S.A. (1995). A stochastic programming model for money management. European Journal of Operational Research, 85, 282-296. http://dx.doi.org/10.1016/0377-2217(94)00038-E

Howison, S.D., Kelly, F.P., \& Wilmott, P. (1995). Mathematical Models in Finance. Chapman \& Hall for the Royal Society, London.

Klaassen, P. (1998). Financial Asset-Pricing Theory and Stochastic Programming Models for Asset/ Liability Management: Management Science. John Wiley \& Sons Ltd, New York.

Korhonen, A. (2001). Strategic financial management in a multinational financial conglomerate: A multiple goal stochastic programming approach. European Journal of Operational Research, 128, 418-434. http://dx.doi.org/10.1016/S0377-2217(99)00366-5

Leornard, D., \& Long, Van N. (1995). Optimal Control Theory and Static Optimization in Economics. Cambridge University Press, Cambridge.

Reserve Bank of Zimbabwe: Bank Licensing, Supervision and Surveillance Guideline No.1-January 2006/ BSd Risk Management. Retrieved from http://www.rbz.co.zw/pdfs/RBZAnnual2006.pdf

Topaloglu, N., Vladimirou, H., \& Zenios, S.A. (2008). A dynamic stochastic programming model for international portfolio management. European Journal of Operational Research, 185, 1501-1524. http://dx.doi.org/10.1016/j.ejor.2005.07.035 


\section{Appendix}

\section{Notation}

$$
\begin{aligned}
& i=1,2 \quad \text { Categories, } \\
& \lambda=\lambda_{1}, \lambda_{2} \quad \text { Constant weights, } \\
& m=1,2,3,4,5,6,7 \text { Categories of bonds according to their maturity dates and types, } \\
& w_{1}=1,2,3 \quad \text { Event } 1 \text { having three scenarios at the end of period } 1, \\
& w_{2}=1,2,3 \quad \text { Event } 2 \text { having three scenarios at the end of period 2, } \\
& \alpha=1,2,3 \quad \text { RBZ interest rate steps, } \\
& u=1,2 \quad \text { Purchase periods of Treasury security assets } A_{1}, A_{2}, A_{3}^{m} \text {, } \\
& \varepsilon=\quad \text { Percentage defined by management, } \\
& s=\quad \text { Selling of Treasury security assets } A_{1}, A_{2}, A_{3}^{m}, \\
& b=\quad \text { Buying of Treasury security assets } A_{1}, A_{2}, A_{3}^{m}, \\
& h=\quad \text { Holding of Treasury security assets } A_{1}, A_{2}, A_{3}^{m}, \\
& y=\quad \text { Income yield from sale of Treasury security assets, } A_{i}, A_{2} \text { and } A_{3}^{m} \text { sold, } \\
& g=\quad \text { Capital gains (loss) on Treasury security assets } A_{i}, A_{2} \text { and } A_{3}^{m} \text { sold, } \\
& r=\quad \text { RBZ Interest rate, } \\
& \vartheta_{i}=\quad \text { Maturity weights of Treasury security assets } A_{i} \text {, where } i=1,2 \\
& \vartheta_{3}^{m}=\quad \text { Maturity weights of Treasury security assets } A_{3}^{m} \text {, where } m=1, \ldots ., 7 \text {. } \\
& k=\quad \text { Time in weeks of the given month, } \\
& \gamma=\quad \text { Time in months of the given year, } \\
& T=\quad \text { Time in days of a given month, } \\
& \varphi=\quad \text { Portfolio type. }
\end{aligned}
$$

\section{Decision Variables}

$A_{i b^{T}}=$ Par value of Treasury security assets $A_{i}$ to buy on day $T$, where $i=1,2$.

$A_{3 b^{T}}^{m}=$ Par value of Treasury security asset $A_{3}^{m}$ to buy on day $T$, where $m=1, \ldots . ., 7$.

$A_{i b_{1}}=$ Par value of Treasury security assets $A_{i}$ bought in period 1 , where $i=1,2$. 
$A_{3 b_{1}}^{m}=$ Par value of Treasury security assets $A_{3}^{m}$ bought in period 1 , where $m=1, \ldots . ., 7$.

$A_{i b_{u w_{1}}}=$ Par value of Treasury security assets $A_{i}$ bought, where $i=1,2 ; u=2$ and $w_{1}=1,2,3$.

$A_{3 b_{u m}}^{m}=$ Par value of Treasury security assets $A_{3}^{m}$ bought, where $u=2$ and $w_{1}=1,2,3$ and

$$
m=1, \ldots . ., 7
$$

$A_{i \rho_{b}^{T}}=$ Buying prices on purchasing of Treasury security asset $A_{i}$ on day $T$, where $i=1,2$.

$A_{3 \rho_{b}^{T}}^{m}=$ Buying prices on purchasing of Treasury security asset $A_{3}^{m}$ on day $T$, where $m=1, \ldots . ., 7$.

$A_{i S}{ }^{T}=$ Par value of Treasury security assets $A_{i}$ to sell on day $T$, where $i=1,2$.

$A_{3 S^{T}}^{m}=$ Par value of Treasury security assets $A_{3}^{m}$ to sell on day $T$, where $m=1, \ldots . ., 7$.

$A_{i S_{u d w}}=$ Par value of Treasury security assets $A_{i}$ sold, where $i=1,2 ; u=1, d=2$ and $w_{1}=1,2,3$.

$A_{3 S_{u d w_{1}}^{m}}^{m}=$ Par value of Treasury security assets $A_{3}^{m}$ sold, where $u=1, d=2$ and $w_{1}=1,2,3$ and

$$
m=1, \ldots ., 7
$$

$A_{i \rho_{s}^{T}}=$ Selling prices on selling Treasury security asset $A_{i}$ on day $T$, where $i=1,2$.

$A_{3 \rho_{s}^{T}}^{m}=$ Selling prices on selling Treasury security asset $A_{3}^{m}$ on day $T$, where $m=1, \ldots \ldots, 7$.

$A_{i h_{D_{R B Z}}}=$ Portion of Treasury security assets $A_{i}$ holdings recognized as reserve deposit in RBZ in week $k$,

where $i=1,2$.

$A_{3 h_{D_{k B Z}^{k}}^{m}}^{m}=$ Portion of Treasury security assets $A_{3}^{m}$ holdings recognized as reserve deposit in RBZ in week

$$
k \text {, where } m=1, \ldots ., 7 \text {. }
$$

$A_{i h_{u d w_{1}}}=$ Par value of Treasury security assets $A_{i}$ held, where $i=1,2 ; u=1, d=2$ and $w_{1}=1,2,3$.

$A_{3 h_{u d w_{1}}^{m}}^{m}=$ Par value of Treasury security assets $A_{3}^{m}$ held, where $u=1, d=2, w_{1}=1,2,3$ and

$$
m=1, \ldots ., 7
$$

$A_{i h_{u d w_{2}}}=$ Par value of Treasury security assets $A_{i}$ held, where $i=1,2 ; u=2, d=3$ and $w_{2}=1,2,3$. 
$A_{3 h_{u d v_{2}}}^{m}=$ Par value of Treasury security assets $A_{3}^{m}$ held, where $u=2, d=3, w_{2}=1,2,3$ and $m=1, \ldots . ., 7$

$A_{\psi h_{u d w_{1}}}=$ Par value of total bank assets (liquid and illiquid assets), $u=1, d=2, w_{1}=1,2,3$ and

$$
\psi=1, \ldots, 5
$$

$A_{\psi h_{u d w_{2}}}=$ Par value of total bank assets (liquid and illiquid assets), $u=2, d=3, w_{1}=1,2,3$ and

$$
\psi=1, \ldots, 5
$$

$A_{i y_{1}}=$ Income yield received on Treasury securities assets $A_{i}$ sold in period 1, where $i=1,2$.

$A_{3 y_{1}}^{m}=$ Income yield received on Treasury securities assets $A_{3}^{m}$ sold in period 1 , where $m=1, \ldots . ., 7$.

$A_{i y_{u m 1}}=$ Income yield received on Treasury security assets $A_{i}$, where $i=1,2 ; u=2$ and $w_{1}=1,2,3$.

$A_{3 y_{u v 1}^{m}}^{m}=$ Income yield received on Treasury security assets $A_{3}^{m}$, where $u=2$ and $w_{1}=1,2,3$ and

$$
m=1, \ldots ., 7
$$

$A_{i g_{u d m}}=$ Capital gains (loss) on Treasury security assets $A_{i}$, where $i=1,2 ; \quad u=1,2 ; d=2,3$ and

$$
w_{1}=1,2,3
$$

$A_{3 g_{u d w 1}^{m}}^{m}=$ Capital gains (loss) on Treasury security assets $A_{3}^{m}$, where $u=1,2 ; d=2,3$ and

$$
w_{1}=1,2,3
$$

$A_{i g_{u d w_{2}}}=$ Capital gains (loss) on Treasury security assets $A_{i}$ sold, where $i=1,2 ; u=1,2 ; d=3$;

$$
w_{1}=1,2,3 \text { and } w_{2}=1,2,3 .
$$

$A_{3 g_{u d w_{2}}^{m}}^{m}=$ Capital gain (loss) on Treasury security asset $A_{3}^{m}$ sold, where $u=1,2, d=3, w_{1}=1,2,3$;

$$
w_{2}=1,2,3 \text { and } m=1, \ldots . ., 7
$$

$A_{i M^{T}}=$ Par value of maturing Treasury security assets $A_{i}$ on day $T$, where $i=1,2$.

$A_{3 M^{T}}^{m}=$ Par value of maturing Treasury security assets $A_{3}^{m}$ on day $T$, where $m=1, \ldots . ., 7$. 
$x_{A_{i}}=$ The proportion of the portfolio's value invested in Treasury security assets $A_{i}$ where $i=1,2$.

$x_{A_{3}^{m}}=$ The proportion of the portfolio's value invested in Treasury security assets $A_{3}^{m}$ where

$$
m=1, \ldots . ., 7
$$

$\delta_{A_{i} A_{j}}=$ The covariance between the returns of the Treasury security assets $A_{i}$ and $A_{j}$,

where $i \neq j, i=1,2$ and $j=1,2$.

$\delta_{A_{i} A_{3}^{m}}=$ The covariance between the returns of the Treasury security assets $A_{i}$ and $A_{3}^{m}$ where $i=1,2$ and $m=1, \ldots . ., 7$.

$\delta_{A_{3}^{m} A_{3}^{m}}=$ The two equivalents conventions for variance of returns of the Treasury security asset $A_{3}^{m}$, where

$$
m=1, \ldots ., 7
$$

$E\left\lfloor R_{A_{i}}\right\rfloor=$ Expected return of investment on Treasury security asset $A_{i}$, where $i=1,2$.

$E\left\lfloor R_{A_{3}^{m}}\right\rfloor=$ Expected return of investment on Treasury security asset $A_{3}^{m}$, where $m=1, \ldots . ., 7$.

$E\left[R_{A_{\varphi}}\right]=$ Expected return of investment on Treasury security asset portfolio,

where

$A_{\varphi}=A_{1}+A_{2}+\sum_{m} A_{3}^{m}$ and $m=1, \ldots ., 7$.

$C_{\text {Bank }}^{T-1}=\quad$ Reserve account balance at the end of the previous day $T-1$ in the bank,

$C_{\text {Bank }_{n}}^{T}=$ Amount of cash to keep in the bank on day $T$,

$C_{a}^{k}=$ Actual amount of vault cash in week $k$ before starting day for the model,

$D_{R B Z}^{T}=$ Amount of deposit in RBZ on day $T$,

$D_{R B Z_{a}}^{k}=$ Actual amount deposited in RBZ in week $k$ before starting day for the model,

$D_{\triangleleft}^{T}=$ Change in demand deposit and credit levels on day $T$,

$D_{R B Z_{\alpha}}^{k}=$ Deposit levels in RBZ in week $k$ on steps $\alpha$, where $\alpha=1,2,3$.

$F_{R B Z}^{k}=$ Fulfillment of RBZ reserve requirement in week $k$, 
$I_{\text {lend }}^{T}=$ Amount to lend overnight in the interbank market on day $T$,

$I_{\text {borr }}^{T}=$ Amount to borrow overnight in the interbank market on day $T$,

$N_{\triangleleft}^{T}=$ Number of calendar days from business day $T$ to business day $T+1$,

$P_{w_{1}}=$ Probability of event $w_{1}$ at the end of period 1 ,

$P_{w_{2} \mid w_{1}}=$ Probability of event $w_{2}$ at the end of period 2 given $w_{1}$, where $w_{1}=1,2,3$ and $\quad w_{2}=1,2,3$.

$Q_{R B Z_{r}}^{T}=$ Credit to be taken from RBZ discount window at interest rate $r$ on day $T$,

$V_{u w_{1}}=$ Maximum par value of Treasury security asset portfolio, where $u=2$ and $w_{1}=1,2,3$.

$\phi_{R B Z}^{k}=$ Penalty for violating RBZ reserve requirements in week $k$,

$\phi_{R B Z}^{\gamma}=$ Penalty for violating RBZ reserve requirements in month $\gamma$,

$\pi_{R B Z}^{\gamma}=$ RBZ required reserve level for current month $\gamma$,

$\operatorname{Min}_{i}=$ Minimum maturity dates for Treasury security assets $A_{i}$, where $i=1,2$.

$\operatorname{Max}_{i}=$ Maximum maturity dates for Treasury security assets $A_{i}$, where $i=1,2$.

$\operatorname{Min}_{3 m}=$ Minimum maturity dates for Treasury security assets $A_{3}^{m}$, where $m=1, \ldots \ldots ., 7$.

$\operatorname{Max}_{3 m}=$ Maximum maturity dates for Treasury security assets $A_{3}^{m}$, where $m=1, \ldots \ldots ., 7$.

\section{Auxiliary Variables}

$R_{A_{i}}=$ Random return of Treasury security assets $A_{i}$, where $i=1,2$.

$R_{A^{*}}=$ Random return of Treasury security assets $A_{3}^{m}$, where $m=1, \ldots \ldots ., 7$.

$R_{A_{\rho}}=$ Random return of the Treasury security asset portfolio $\varphi$,

$e_{\text {fund }}=$ Cost of funding assets,

$e_{\text {earr }}=$ Cost of funding earning assets,

$e_{\text {int }}=$ Average interest expenses on deposits,

$e_{\text {bor }}=$ Average cost of borrowed funds. 
$e_{\text {misc }}=$ Miscellaneous expenses.

Two months are considered in this paper. The second set of decisions are made at the end of second one-month period, a new random event occurs and the portfolio is then sold for cash. Thus the model covers two one-month time periods, with portfolio decisions made at the start of each period and the final value of the portfolio determined at the end of the second period.

Treasury security assets are purchased at the start of periods 1 and 2, thus $w_{1}$ and $w_{2}$ respectively. Treasury security assets can be sold at the start of period 2 and must be sold at the end of that period, thus $d=2$ and $d=3$. Three random events can occur just before decisions are made at the start of period 2 . The set of events are denoted by $w_{1}=1,2,3$. There are upper limits on the total size of portfolio $\left(V_{u w_{1}}\right)$ generated by these decisions. All decision variables and right-hand side values are defined in terms of Zimbabwean dollars (Z\$). The commercial banks have to follow special accounting practices and tax regulations. The profits from these decisions are broken down into components, an income yield $(y)$ stemming from coupon interest on the treasury security assets sold. Both of these coefficients are defined as after taxes, and the gain coefficient also takes into consideration the broker's commission. In this paper capital gains tax has been treated as income tax rate. Thus we assume that the income tax rate is $\tau \%$ if security sales in the two-model periods result in the net positive gains. If sales result in losses, there is a tax savings based upon the income tax rate and we assume it to be $\varpi \%$ (Zenios, 1993).

\section{Two-Stage Stochastic Programming Model}

$$
\begin{aligned}
& \operatorname{Min} x_{A_{1}}^{2} \delta_{A_{1} A_{1}}+x_{A_{2}}^{2} \delta_{A_{2} A_{2}}+\sum_{m}\left(x_{A_{3}^{m}}\right)^{2} \delta_{A_{3}^{m} A_{3}^{m}} \\
& +2 x_{A_{1}} x_{A_{2}} \delta_{A_{1} A_{2}}+2 x_{A_{1}} \sum_{m} x_{A_{3}^{m}} \delta_{A_{1} A_{3}^{m}}+2 x_{A_{2}} \sum_{m} x_{A_{3}^{m}} \delta_{A_{2} A_{3}^{m}} \\
& +\lambda_{1}\left[x_{A_{1}} E\left[R_{A_{1}}\right]+x_{A_{2}} E\left[R_{A_{2}}\right]+\sum_{m} x_{A_{3}^{m}} E\left[R_{A_{3}^{m}}\right]-E\left[R_{A_{\varphi}}\right]\right] \\
& +\lambda_{2}\left[\left(x_{A_{1}}+x_{A_{2}}+\sum_{m} x_{A_{3}^{m}}\right)-1\right]+E\left[Z\left(A_{1}, A_{2}, A_{3}^{m}\right)\right] \\
& \text { s.t } \quad 2 x_{A_{1}} \delta_{A_{1} A_{1}}+2 x_{A_{2}} \delta_{A_{2} A_{2}}+2 \sum_{m} x_{A_{3}^{m}} \delta_{A_{1} A_{3}^{m}}=\lambda_{1} E\left\lfloor R_{A_{1}}\right\rfloor-\lambda_{2} \\
& { }^{2} x_{A_{2}} \delta_{A_{2} A_{2}}+2 x_{A_{1}} \delta_{A_{1} A_{2}}+2 \sum_{m} x_{A_{3}^{m}} \delta_{A_{2} A_{3}^{m}}=\lambda_{1} E\left\lfloor R_{A_{2}}\right\rfloor-\lambda_{2} \\
& 2 \sum_{m} x_{A_{3}^{m}} \delta_{A_{3}^{m} A_{3}^{m}}+2 x_{A_{1}} \sum_{m} \delta_{A_{1} A_{3}^{m}}+2 x_{A_{2}} \sum_{m} \delta_{A_{2} A_{3}^{m}}=\lambda_{1} \sum_{m} E\left\lfloor R_{A_{3}^{m}}\right\rfloor-\lambda_{2} \\
& x_{A_{1}} E\left[R_{A_{1}}\right]+x_{A_{2}} E\left[R_{A_{2}}\right]+\sum_{m} x_{A_{3}^{m}} E\left[R_{A_{3}^{m}}\right]=E\left[R_{A_{\varphi}}\right] \\
& x_{A_{1}}+x_{A_{2}}+\sum_{m} x_{A_{3}^{m}}=1
\end{aligned}
$$




$$
\begin{aligned}
& x_{A_{1}} \geq 0 \\
& x_{A_{2}} \geq 0 \\
& \sum_{m} x_{A_{3}^{m}} \geq 0
\end{aligned}
$$

where $x_{A_{1}}, x_{A_{2}}$ and $x_{A_{3}^{m}}$ are first-stage anticipative decisions (made before random variables are observed), where $m=1, \ldots ., 7$. Also $Z\left(A_{1}, A_{2}, A_{3}^{m}\right)$ is the optimal value of the linear program (second-stage model). Thus equation (1) is the Makowirtz objective function (first stage model) plus the expectation of the optimal value of the second stage model.

\section{Second Stage Model}

$$
\begin{aligned}
& \text { Min } \quad e_{\text {fund }}+\boldsymbol{e}_{\text {earn }}+\boldsymbol{e}_{\mathrm{int}}+\boldsymbol{e}_{\text {borr }}+\boldsymbol{e}_{\text {misc }} \\
& \text { s.t } \quad-A_{1 b_{1}}+A_{1 S_{121}}+A_{1 h_{121}}=0 \\
& -A_{1 b_{1}}+A_{1 S_{122}}+A_{1 h_{122}}=0 \\
& -A_{1 b_{1}}+A_{1 S_{123}}+A_{1 h_{123}}=0 \\
& -A_{2 b_{1}}+A_{2 S_{121}}+A_{2 h_{121}}=0 \\
& -A_{2 b_{1}}+A_{2 S_{122}}+A_{2 h_{122}}=0 \\
& -A_{2 b_{1}}+A_{2 s_{123}}+A_{2 h_{123}}=0 \\
& -A_{3 b_{1}}^{m}+A_{3 S_{121}}^{m}+A_{3 h_{121}}^{m}=0 \\
& -A_{3 b_{1}}^{m}+A_{3 S_{122}}^{m}+A_{3 h_{122}}^{m}=0 \\
& -A_{3 b_{1}}^{m}+A_{3 S_{123}}^{m}+A_{3 h_{123}}^{m}=0 \\
& D_{R B Z_{a}}^{k}+\sum_{T \in K} D_{R B Z}^{T} N_{\triangleleft}^{T}=D_{R B Z_{\alpha}}^{k} \\
& \sum_{T \in K}\left[D_{R B Z}^{T}+C_{B_{a n k}}^{T}\right] N_{\triangleleft}^{T}+D_{R B Z_{a}}^{k}+C_{a}^{k}=F_{R B Z}^{k} \\
& \sum_{T \in K}\left[F_{R B Z}^{k}+A_{1 h_{D_{R B Z}^{k}}^{k}}+A_{2 h_{D_{R B Z}^{k}}}+A_{3 h_{D_{R B Z}^{k}}^{m}}^{m}+\phi_{R B Z}^{k}\right]+\phi_{R B Z}^{\gamma} \geq \pi_{R B Z}^{\gamma}
\end{aligned}
$$




$$
\begin{aligned}
& C_{\text {Bank }}^{T-1}+D_{\triangleleft}^{T}+\sum_{r} Q_{R B Z_{r}}^{T}+I_{b o r r}^{T}+A_{1 \rho_{s}^{T}} A_{1 s^{T}}+A_{2 \rho_{s}^{T}} A_{2 s^{T}}+\sum_{m} A_{3}^{m} \rho_{s}^{T} A_{3 s^{T}}^{m}+A_{1 M^{T}}+A_{2 M^{T}}+\sum_{m} A_{3 M^{T}}^{m} \\
& D_{R B Z}^{T}+C_{\text {Bank }_{h}^{T}}^{+} A_{1} \rho_{b}^{T} A_{1 b^{T}}+A_{2 \rho_{b}^{T}} A_{2 b^{T}}+\sum_{m} A_{3 \rho_{b}^{T}}^{m} A_{3 b^{T}}^{m}+I_{\text {lend }}^{T} \\
& A_{1 b_{1}} \leq P_{1} \\
& A_{2 b_{1}} \leq P_{1} \\
& \sum_{m} A_{3 b_{1}}^{m} \leq P_{1} \\
& \text { - } A_{1 y_{1}} A_{1 b_{1}}-A_{1 g_{121}} A_{1 S_{121}}+A_{1 h_{121}}+A_{1 b_{21}} \leq V_{21} \\
& \text { - } A_{1 y_{1}} A_{1 b_{1}}-A_{1 g_{122}} A_{1 S_{122}}+A_{1 h_{122}}+A_{1 b_{22}} \leq V_{22} \\
& \text { - } A_{1 y_{1}} A_{1 b_{1}}-A_{1 g_{123}} A_{1 S_{123}}+A_{1 h_{123}}+A_{1 b_{23}} \leq V_{23} \\
& \text { - } A_{2 y_{1}} A_{2 b_{1}}-A_{2 g_{121}} A_{2 S_{121}}+A_{2 h_{121}}+A_{2 b_{21}} \leq V_{21} \\
& \text { - } A_{2 y_{1}} A_{2 b_{1}}-A_{2 g_{122}} A_{2 s_{122}}+A_{2 h_{122}}+A_{2 b_{22}} \leq V_{22} \\
& -A_{2 y_{1}} A_{2 b_{1}}-A_{2 g_{123}} A_{2 s_{123}}+A_{2 h_{123}}+A_{2 b_{23}} \leq V_{23} \\
& -\sum_{m} A_{3 y_{1}}^{m} A_{3 b_{1}}^{m}-\sum_{m} A_{3 g_{121}}^{m} A_{3 S_{121}}^{m}+\sum_{m} A_{3 h_{121}}^{m}+\sum_{m} A_{3 b_{21}}^{m} \leq V_{21} \\
& -\sum_{m} A_{3 y_{1}}^{m} A_{3 b_{1}}^{m}-\sum_{m} A_{3 g_{122}}^{m} A_{3 S_{122}}^{m}+\sum_{m} A_{3 h_{122}}^{m}+\sum_{m} A_{3 b_{22}}^{m} \leq V_{22} \\
& -\sum_{m} A_{3 y_{1}}^{m} A_{3 b_{1}}^{m}-\sum_{m} A_{3 g_{123}}^{m} A_{3 S_{123}^{m}}^{m}+\sum_{m} A_{3 h_{123}^{m}}^{m}+\sum_{m} A_{3 b_{23}}^{m} \leq V_{23} \\
& \varepsilon \sum_{\psi} A_{\psi h_{121}} \leq A_{1 h_{121}}+A_{2 h_{121}}+\sum_{m} A_{3 h_{121}^{m}}^{m} \\
& \varepsilon \sum_{\psi} A_{\psi h_{122}} \leq A_{1 h_{122}}+A_{2 h_{122}}+\sum_{m} A_{3 h_{122}}^{m} \\
& \varepsilon \sum_{\psi} A_{\psi h_{123}} \leq A_{1 h_{123}}+A_{2 h_{123}}+\sum_{m} A_{3 h_{123}}^{m} \\
& \operatorname{Min}_{1} \leq \vartheta_{1} A_{1 h_{121}} \leq \operatorname{Max}_{1} \\
& \operatorname{Min}_{1} \leq \vartheta_{1} A_{1 h_{122}} \leq \operatorname{Max}_{1} \\
& \operatorname{Min}_{1} \leq \vartheta_{1} A_{1 h_{123}} \leq \operatorname{Max}_{1} \\
& \operatorname{Min}_{2} \leq \vartheta_{2} A_{2 h_{121}} \leq \operatorname{Max}_{2}
\end{aligned}
$$




$$
\begin{aligned}
& \operatorname{Min}_{2} \leq \vartheta_{2} A_{2 h_{122}} \leq \operatorname{Max}_{2} \\
& \operatorname{Min}_{2} \leq \vartheta_{2} A_{2 h_{123}} \leq \operatorname{Max}_{2} \\
& \operatorname{Min}_{m} \leq \sum_{m} \vartheta_{3}^{m} A_{3 h_{121}^{m}}^{m} \leq \operatorname{Max}_{m} \\
& \operatorname{Min}_{m} \leq \sum_{m} \vartheta_{3}^{m} A_{3 h_{122}^{m}}^{m} \leq \operatorname{Max}_{m} \\
& \operatorname{Min}_{m} \leq \sum_{m} \vartheta_{3}^{m} A_{3 h_{123}}^{m} \leq \operatorname{Max}_{m} \\
& \text { - } A_{1 g_{121}} A_{1 S_{121}}-A_{1 g_{131}} A_{1 h_{121}}-A_{1 g_{231}} A_{1 b_{21}} \leq L \\
& \text { - } A_{1 g_{122}} A_{1 S_{122}}-A_{1 g_{132}} A_{1 h_{122}}-A_{1 g_{232}} A_{1 b_{22}} \leq L \\
& \text { - } A_{1 g_{123}} A_{1 S_{123}}-A_{1 g_{133}} A_{1 h_{123}}-A_{1 g_{233}} A_{1 b_{23}} \leq L \\
& \text { - } A_{2 g_{121}} A_{2 S_{121}}-A_{2 g_{131}} A_{2 h_{121}}-A_{2 g_{231}} A_{2 b_{21}} \leq L \\
& \text { - } A_{2 g_{122}} A_{2 S_{122}}-A_{2 g_{132}} A_{2 h_{122}}-A_{2 g_{232}} A_{2 b_{22}} \leq L \\
& \text { - } A_{2 g_{123}} A_{2 S_{123}}-A_{2 g_{133}} A_{2 h_{123}}-A_{2 g_{233}} A_{2 b_{23}} \leq L \\
& -\sum_{m} A_{3 g_{121}}^{m} A_{3 S_{121}}^{m}-\sum_{m} A_{3 g_{131}}^{m} A_{3 h_{121}}^{m}-\sum_{m} A_{3 g_{231}}^{m} A_{3 b_{21}}^{m} \leq L \\
& -\sum_{m} A_{3 g_{122}}^{m} A_{3 S_{122}^{m}}^{m}-\sum_{m} A_{3 g_{132}^{m}}^{m} A_{3 h_{122}^{m}}^{m}-\sum_{m} A_{3 g_{232}}^{m} A_{3 b_{22}}^{m} \leq L \\
& \left(-\sum_{m} A_{3 g_{123}^{m}}^{m} A_{3 S_{123}^{m}}^{m}-\sum_{m} A_{3 g_{133}}^{m} A_{3 h_{123}^{m}}^{m}-\sum_{m} A_{3 g_{233}}^{m} A_{3 b_{23}}^{m} \leq L\right. \\
& E\left[R_{A_{\varphi}}\right]=\sum_{w_{1}} P_{w_{1}}\left[\sum_{w_{2}} P_{w_{2} \mid w_{1}} R_{A_{q w_{1}}}+\sum_{w_{2}} P_{w_{2} \mid w_{1}} R_{A_{q w_{2}}}\right]
\end{aligned}
$$

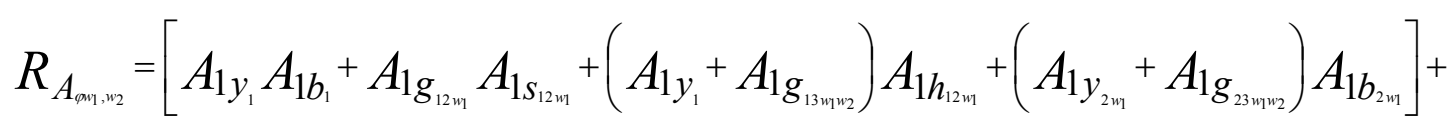

$$
\begin{aligned}
& {\left[A_{2 y_{1}} A_{2 b_{1}}+A_{2 g_{12 w_{1}}} A_{2 S_{12 m_{1}}}+\left(A_{2 y_{1}}+A_{2 g_{13 \text { m. }}}\right) A_{2 h_{12 w_{1}}}+\left(A_{2 y_{2 m 1}}+A_{2 g_{23 m_{2}}}\right) A_{2 b_{2 w_{1}}}\right]+} \\
& \sum_{m}\left[A_{3 y_{1}}^{m} A_{3 b_{1}}^{m}+A_{3 g_{12 m}}^{m} A_{3 S_{12 m}^{m}}^{m}+\left(A_{3 y_{1}}^{m}+A_{3 g_{13 m w_{2}}}^{m}\right) A_{3 h_{12 m}^{m}}^{m}+\left(A_{3 y_{2 m 1}^{m}}^{m}+A_{3 g_{23 m m_{2}}^{m}}\right) A_{3 b_{2 m}}^{m}\right] \\
& A_{i b_{1}} \geq 0, A_{i b^{T}} \geq 0, A_{i b_{2 m}} \geq 0, A_{3 b_{1}}^{m} \geq 0, A_{3 b^{r}}^{m} \geq 0, A_{3 b_{2 m}}^{m} \geq 0
\end{aligned}
$$




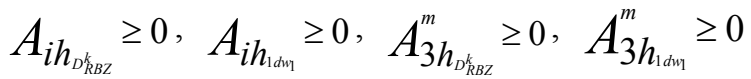

$$
\begin{aligned}
& A_{i S^{T}}{ }^{T} \geq 0, \quad A_{i S_{\text {ldw }}} \geq 0, \quad A_{3 S^{T}}^{m} \geq 0, \quad A_{3 h_{\text {ldv }}}^{m} \geq 0 \\
& A_{i M^{T}} \geq 0, \quad A_{3 M^{T}}^{m} \geq 0
\end{aligned}
$$

where $i=1,2, w_{1}=1,2,3$ and $w_{2}=1,2,3$.

Thus $A_{1}, A_{2}$ and $A_{3}^{m}$ are second-stage adaptive decisions (depending on the realization of the first-stage random vector).

The objective function (1) is to minimize costs to maximize expected returns per investment. Francis (1991) pointed out that Markowirtz diversification combines assets which are less than positively correlated in order to reduce portfolio risk without sacrificing portfolio returns. The model considers assets' correlations (covariances). Thus the lower the correlation between assets, the more that Markowirtz diversification will be able to reduce the portfolio's risk. The first-stage model has two assumptions which are;

1) The maximum size of the portfolio is determined outside the model framework.

2) As long as the portfolio decisions satisfy the constraints imposed by the rest of the bank, portfolio strategies can be selected without regard to the return or risk associated with other bank assets.

The two-stage SP model seeks to minimize costs of the first-period decision plus the expected costs of the second-period recourse decision,

$$
\text { where } \boldsymbol{e}_{\text {fund }}+\boldsymbol{e}_{\text {earn }}+\boldsymbol{e}_{\mathrm{int}}+\boldsymbol{e}_{\text {borr }}+\boldsymbol{e}_{\text {misc }}
$$

is the cost function explaining the costs associated with the investment of treasury security assets portfolio. 